Responsible Editor: Maria Dolores Sánchez-Fernández, Ph.D. Associate Editor: Manuel Portugal Ferreira, Ph.D.

\title{
EDITORIAL \\ (RE)PENSAR SOBRE AS CIDADES CONTEMPORÂNEAS: CONTRIBUIÇÕES AO DEBATE
}

\author{
Giovana Goretti Feijó de Almeidai \\ http://www.openaccessojs.com/JBReview/article/view/207
}

As cidades de hoje são diferentes das cidades do passado. Tornaram-se mais complexas, mais densas e com vários problemas em comum, como é o caso dos resíduos sólidos urbanos, mobilidade urbana e da sustentabilidade ambiental, por exemplo. As necessidades dos cidadãos são diversas, mas similares a inúmeras outras cidades no mundo todo. O viver em uma cidade estabelece relações com o urbano e com a natureza, bem como pressupõe a existência do que Raffestin (1993) chamou de território vivido em contraste com o que Pecqueur (2005) denominou de território dado. A cidade é um espaço multifacetado por outros territórios que muitas vezes se sobrepõem. Outras vezes contrastam e disputam espaço (físico e simbólico), o que thes proporciona um diálogo urbano por meio de seus conflitos, parcerias e relações que estabelece entre si e com o meio ambiente.

As cidades têm sido foco de discussões globais, como: sustentabilidade, planejamento urbano, moradias para pessoas de baixa renda, periferia, conflito e parcerias entre atores sociais, identidade territorial e cultural, densidade, população, mobilidade, inteligência das cidades, cidades digitais e estratégicas, cidades virtuais, marcas de cidades, imagem da cidade, fluxos, migrações, energia sustentável. A cada marco temporal os espaços urbanos vão se redescobrindo e se reinventando, levando a novos usos e apropriações, bem como conflitando ou corroborando com a pluralidade de discursos e práticas que lhe abarcam cotidianamente.

Espaços urbanos surgem em locais antes subutilizados ou vazios, como o caso dos Pocket Parks e dos Parklets (Purper, Rigati \& Almeida, 2019) ou os telhados urbanos (Almeida \& Engel, 2018). Identidades afloram e disputam territórios simbólicos com as identidades hegemônicas que se valem de

marcas territoriais (Almeida, 2018). Criam-se rankings urbanos que elencam as melhores e as piores cidades para se viver, fazer negócios, morar e visitar (Almeida, 2019). A imagem do espaço público urbano é reconstruído simbolicamente (Almeida \& Engel, 2017). Surgem novas oportunidades e desafios para as cidades do Século XXI (Almeida \& Engel, 2109), incluindo sua reconstrução simbólica (Almeida, 2019; Almeida, 2020). Há um paradoxo em que marcas promovem território, territórios promovem marcas, e se alastram aos territórios percebidos como marcas (Almeida, 2018; 2019).

Fluxos emergem dos problemas urbanos compartilhados. Problemas velhos demandam "novas" soluções sustentáveis ambientalmente. A cidade é plural por natureza e seus problemas acompanham a dinâmica de seu mosaico de territórios. Com o tempo, essas relações ficam cada vez mais complexas, demandando reflexões e novas práticas. Faz-se necessário aprofundar os desafios das cidades frente à realidade de uma imensa população urbana que cresce diariamente. Frente ao exposto, o Dossiê Temático "Desafios urbanos nas cidades contemporâneas" pretende contribuir com reflexões acerca das realidades urbanas atuais.

Assim, com imensa satisfação apresentamos o Dossiê "Urban Challenges in Contemporary Cities", com a participação da editora convidada Dra. Giovana Goretti Feijó de Almeida. A pesquisadora possui Pós-Doutorado em Gestão Urbana com ênfase em Cidade Digital Estratégica pela Pontifícia Universidade Católica do Paraná (PPGTU-PUCPR, Brasil), Doutorado e Mestrado em Desenvolvimento Regional pela Universidade de Santa Cruz do Sul (UNISC, Brasil). Recebeu Menção Honrosa no Prêmio Capes de Teses 2019, área Planejamento UrbanoRegional e Demografia. Bacharela em Comunicação 
Social com pós-graduação lato sensu em Branding (UNISC). Professora-Visitante no PPGTU/PUCPR (2018-2020, Brasil). Pesquisadora-integrante do Grupo de Pesquisas sobre Cidades Digitais Estratégicas (PPGTU/PUCPR, Brasil) e vice-líder no ESTTTER - grupo de estudos sobre Território, Territorialidades e Territorializações (UNIR/CNPq, Brasil). É pesquisadora no Center for Tourism Research, Development, and Innovation (CITUR, Portugal). Desde dezembro de 2019 é Membro no Parlamento Mundial da Educação. Autora dos livros "Identidade Territorial e Branding de Marcas Regionais" e "Marcas e Territórios". Possui mais de 50 publicações nacionais e internacionais sobre os temas: desenvolvimento urbano-regional, cidades, marcas territoriais, place branding, territórios e cidade digital estratégica.

A edição de janeiro-junho 2020 da JPBReview traz dois artigos do Dossiê "Urban Challenges in Contemporary Cities". Um dos artigos é sobre as microescalas do Desenvolvimento Regional que abordam o Direito à Cidade de Pessoas LGBTQI+, cuja autoria é dos pesquisadores, Mariana Barbosa de Souza e Marcio Jose Ornat. O segundo é de autoria de Edson Modesto de Araújo Júnior que investigou a cartografia social nas narrativas dos territórios pode ser aplicada ao territórios urbanos. O pesquisador apresentou o caso das populações ribeirinhas na Região conhecida como Amazônia Legal, no Brasil.

Na edição de julho-dezembro 2020 da JPBReview são apresentados oito discussões sobre as cidades. Jussara Ribeiro Lopes e Fernando de Almeida Santos debatem o déficit das moradias precárias na região central de São Paulo, Brasil. Já Thiago de Souza Beté, Diego De Melo Conti, Meriellen Nuvolari Pereira Mizutani e Carlos Alberto Nunes de Oliveiraa abordam a possibilidade de veículos sustentáveis para a mobilidade urbana nas cidades do futuro. A autora Sarah Marroni Minasi nos traz as possibilidades do sensoriamento remoto nas pesquisas sobre urbanização turística. Juscelino Gomes Lima investiga os sertões do Piauí por meio dos dilemas e desafios para a gestão urbana em uma cidade de comando regional piauiense. Os autores Juliana Fabris, Rógis Juarez Bernardy, Simone Sehnem e Andrezza Aparecida Saraiva Piekas trazem a reflexão sobre os caminhos e possibilidades das cidades sustentáveis. Já Renata Maria Aponte Rodrigues de Carvalho discute as cidades inteligentes e a participação cidadã. Lucília Cardoso, Noélia e
Angela levantam a questão da La imagen Top of Mind de un destino turístico durante un Mega-evento por meio do estudo de El caso de Viana do Castelo y el Festival Vodafone Paredes de Coura. E os autores Rylanneive Leonardo Pontes Teixeira e Zoraide Souza Pessoa pesquisam as mudanças climáticas, experimentação de políticas públicas e a capacidade adaptativa na cidade de Curitiba, Brasil. As discussões e temáticas abarcam múltiplas perspectivas sobre as cidades contemporâneas que devido a sua complexidade se distinguem das cidades de séculos passados.

\section{Referências}

ALMEIDA, G. G. F. (2020). Apropriação simbólica do território por meio das marcas. In: Mizael Dornelles (Org.). Desenvolvimento Regional: diferentes leituras em convergência. 1ed.Santa Cruz do Sul-RS: The Help, 2020, v. 1, p. 161-183.

ALMEIDA, G. G. F. (2019). The Role of Urban Rankings in the Construction of Perception on Innovation In Smart Cities. International Journal of Innovation, 7(1), 119-134. http://www.journaliji.org/index.php/iji/article/view/ 381

ALMEIDA, G. G. F. (2019). Múltiplas perspectivas sobre a inteligência das smart cities. International Journal of Professional Business Review, v.4, p. 147151.

ALMEIDA, G. G. F. (2019). Marcas e territórios: a construção simbólica de Porto Alegre. 1. ed. Santa Cruz do Sul-RS: The Help.

ALMEIDA, G. G. F.; ENGEL, V. (Org.) (2019). Inovação e cidades inteligentes: desafios $e$ oportunidades nas cidades do Século XXI. 1. ed. Santa Cruz do Sul: The Help.

ALMEIDA, G. G. F. (2018). Marca territorial como produto cultural no âmbito do Desenvolvimento Regional: o caso de Porto Alegre, RS, Brasil. Tese de Doutorado, Programa de Pós-Graduação em Desenvolvimento Regional, Universidade de Santa Cruz do Sul, Brasil.

ALMEIDA, G. G. F.; ENGEL, V. (2017). A cidademercadoria e o marketing urbano na (re)construção da imagem dos espaços públicos: o caso da marca da 
cidade do Rio de Janeiro. Revista Brasileira de Estudos Urbanos e Regionais (ANPUR), v. 19, p. 89-105.

ALMEIDA, G. G. F.. (2017). A identidade territorial $e$ o branding de marcas regionais: marcas promovendo territórios ou territórios promovendo marcas. 1. ed. Santa Cruz do Sul: The Help.

PECQUEUR, B. (2005). O desenvolvimento territorial: uma nova abordagem dos processos de desenvolvimento para as economias do sul. Raízes, Campina Grande, Vol. 24, no 01 e 02, jan./dez.
PURPER, V. ; RIGATI, D. ; ALMEIDA, G. G. F. . (2019). Compact public spaces as intelligent connection spaces: the pocket parks in São Paulo, Brazil. In: ALMEIDA, G. G. F.; ENGEL, V.. (Org.). Inovação e cidades inteligentes: desafios $e$ oportunidades nas cidades do Século XXI. 1ed.Santa Cruz do Sul: The Help, p. 255-267.

RAFFESTIN, C. Por uma geografia do poder. São Paulo: Ática, 1993.

\footnotetext{
i Pesquisadora no Center for Tourism Research, Development, and Innovation (CITUR, Portugal). Doutora em Desenvolvimento Regional pela UNISC (2018) com estágio pós-doutoral no PPGTU/PUCPR em cidade digital estratégica (2020). Mestra em Desenvolvimento Regional (UNISC, 2015). Recebeu Menção Honrosa no Prêmio Capes de Teses 2019, área PUR/D. Bacharela em Comunicação Social com pós-graduação lato sensu em Branding (UNISC). ProfessoraVisitante no PPGTU/PUCPR (2018-2020). Pesquisadora-integrante do Grupo de Pesquisas sobre Cidades Digitais Estratégicas (PPGTU/PUCPR) e vice-líder no ESTTTER - grupo de estudos sobre Território, Territorialidades e Territorializações (UNIR/CNPq). Membro no Parlamento Mundial da Educação. Autora do livro "Identidade Territorial e Branding de Marcas Regionais" e "Marcas e Territórios". E-mail: goretti.giovana@gmail.com - currículo lattes: http://lattes.cnpq.br/7793741520961755 Orcid id: https://orcid.org/0000-0003-0956-1341
} 